\title{
A família Passifloraceae na APA Serra Branca/Raso da Catarina, Jeremoabo, Bahia, Brasil
}

\author{
Jéssica Vieira dos Santos ${ }^{1^{*}}$ \\ Teonildes Sacramento Nunes ${ }^{2}$ \\ Adilva de Souza Conceição ${ }^{1}$ \\ ${ }^{1}$ Universidade do Estado da Bahia, Departamento de Educação, Campus VIII, \\ Herbário HUNEB (Coleção Paulo Afonso), Rua do Gangorra, 503, CHESF, CEP 48608-240, Paulo Afonso - BA, Brasil \\ ${ }^{2}$ Universidade Estadual de Feira de Santana, Departamento de Ciências Biológicas, Herbário HUEFS \\ Avenida Universitária, s/n, Novo Horizonte, CEP 44036-900, Feira de Santana - BA, Brasil \\ * Autor para correspondência \\ ddi_jessica@hotmail.com
}

Submetido em 17/05/2015

Aceito para publicação em 20/10/2015

\section{Resumo}

Este trabalho apresenta o levantamento florístico da família Passifloraceae na APA Serra Branca/Raso da Catarina, localizada no município de Jeremoabo, Bahia. A família inclui cerca de 20 gêneros e 600 espécies, de distribuição pantropical. No Brasil, ocorrem quatro gêneros: Ancistrothyrsus, Dilkea, Mitostemma e Passiflora, sendo o último o mais representativo. Para o bioma Caatinga são citadas 29 espécies, incluindo uma espécie de Mitostemma e as demais de Passiflora. Os espécimes analisados foram coletados no período de agosto/2011 a fevereiro/2013, as análises foram complementadas com coleções herborizadas depositadas nos herbários: ALCB, HRB e HUEFS. Foram catalogadas quatro espécies do gênero Passiflora: Passiflora cincinnata, P. foetida, P. luetzelburgii e $P$. setacea. São apresentados comentários sobre morfologia e taxonomia, ilustrações, dados sobre distribuição geográfica e fenologia, além de uma chave para os táxons estudados.

Palavras-chave: Biodiversidade; Caatinga; Florística

\section{Abstract}

The family Passifloraceae in APA Serra Branca/Raso da Catarina, Jeremoabo, Bahia, Brazil. This work presents a floristic survey of the family Passifloraceae in APA Serra Branca/Raso da Catarina, located in the municipality of Jeremoabo, Bahia. The family has a pantropical distribution and includes about 20 genera and 600 species. In Brazil there are four genera, Ancistrothyrsus, Dilkea, Mitostemma and Passiflora, the latter being the most diverse. In the Caatinga biome there are 29 species, including one species of Mitostemma and the others of Passiflora. The samples analyzed were collected from August/2011 to February/2013, and the analyses were supplemented with dried collections kept in the following herbaria: ALCB, HRB and HUEFS. Four species of the genus Passiflora were recorded: Passiflora cincinnata, P. foetida, P. luetzelburgii and $P$. setacea. Comments about the morphology and taxonomy, data on geographical distribution and phenology, illustrations, and a key to the taxa studied are provided.

Keywords: Biodiversity; Caatinga; Floristic 


\section{Introdução}

A família Passifloraceae Juss. ex Roussel inclui cerca de 16 gêneros (KROSNICK et al., 2009) e aproximadamente 630 espécies de ocorrência pantropical (ULMER; MACDOUGAL, 2004; JUDD et al., 2009), sendo encontrada ao longo dos trópicos e subtrópicos, com algumas espécies atingindo regiões temperadas (JUDD et al., 2009).

Dentre os trabalhos mais relevantes para taxonomia da família, podemos destacar os de: Linnaeus (1753), que reconheceu 24 espécies de Passiflora na obra Species Plantarum; a monografia Prodomus (DE CANDOLLE, 1828), em que foram descritas 145 espécies de Passifloraceae; Masters (1872), que publicou 204 espécies americanas, dentre estas 82 foram citadas para o Brasil na Flora Brasiliensis; e Killip (1938), que descreveu 355 espécies de Passiflora para a América, das quais 101 são citadas para o Brasil, na The American Species of Passifloraceae, sendo uma das obras mais completas para o grupo. Feuillet e MacDougal (2003 [2004]) propuseram uma nova classificação infragenérica para Passiflora, reconhecendo quatro subgêneros: Astrophea (DC.) Mast., com 27 espécies; Decaloba (DC.) Rchb., com 214 espécies; Deidamioides (Harms) Killip, com 13 espécies; e Passiflora L., com aproximadamente 236 espécies.

Para o Brasil, são citados quatro gêneros: Ancistrothyrsus Harms; Dilkea Mast.; Mitostemma Mast. e Passiflora L., este último é numericamente o mais representativo da família, possuindo 142 das 150 espécies encontradas no país (BERNACCI et al., 2015). No bioma Caatinga, foram catalogadas uma espécie de Mitostemma (M. glaziovii Mast.) e 28 espécies de Passiflora, destacando-se a Caatinga baiana por possuir 23 espécies do último gênero (BERNACCI et al., 2015).

Tratamentos envolvendo levantamentos florísticos e revisões taxonômicas que contribuíram para o conhecimento da família no Brasil foram desenvolvidos por: Sacco (1980), Pessoa (1994), Cervi (1997; 2000), Cervi e Dunaiski Junior (2004), Bernacci (2003), Milward-de-Azevedo e Baumgratz (2004), Milward-deAzevedo e Valente (2004), Farinazzo e Salimena (2007), Feuillet e MacDougal (2007), Milward-de-Azevedo
(2007), Cervi e Linsingen (2008), Nunes (2009), Silva et al. (2013) e Vanderplank (2013). Para a região Nordeste do Brasil, são poucos os estudos taxonômicos realizados para Passifloraceae, dentre os quais podem ser citados os trabalhos de Vitta (1995), Sena e Queiroz (1998), Nunes e Queiroz (2001; 2006) e Costa et al. (2015).

Apesar da existência de estudos sobre Passifloraceae para o Nordeste, trabalhos específicos para Caatinga do estado da Bahia são escassos, especialmente os que incluem chaves de identificação e descrições. Diante da importância da família na vegetação de Caatinga, o presente trabalho teve como objetivo realizar o levantamento das espécies da família Passifloraceae ocorrentes na APA Serra Branca/Raso da Catarina, visando contribuir para o conhecimento científico da Ecorregião Raso da Catarina, bem como fornecer subsídios para o desenvolvimento do plano de manejo da APA.

\section{Material e Métodos}

A APA Serra Branca/Raso da Catarina (Figura 1) está localizada no município de Jeremoabo, nordeste da Bahia, totalmente inserida no "polígono das secas", a 371 km de Salvador, com uma área de 67.237 ha, delimitada pelas coordenadas $09^{\circ} 53^{\prime} 15.5^{\prime \prime}$ a $09^{\circ} 44^{\prime} 34.6$ "S e $38^{\circ} 49^{\prime} 36.1^{\prime \prime}$ a $38^{\circ} 52^{\prime} 20.4^{\prime \prime} \mathrm{W}$, limitando-se ao sul com o rio Vaza-Barris e ao norte com a Estação Ecológica (ESEC) Raso da Catarina. A Caatinga predomina em praticamente toda a região, com clima semiárido, apresentando temperaturas médias anuais em torno de $23^{\circ} \mathrm{C}$ e precipitações anuais que variam em torno de 500 $\mathrm{mm}$. O relevo da região é plano com formações areníticas e predominância de solos arenosos (VELLOSO et al., 2002; SZABO et al., 2007).

Foram realizadas nove excursões mensais de campo para coleta do material botânico, no período de agosto/2011 a fevereiro/2013, seguindo a metodologia de Fosberg e Sachet (1965) e Mori et al. (1989), onde foram coletados materiais férteis com flores e/ou frutos, e feitas observações sobre a distribuição das espécies e os tipo de solo. Os espécimes foram depositados no herbário da Universidade do Estado da Bahia (HUNEB - Coleção Paulo Afonso), as duplicatas serão enviadas para os principais herbários do estado da Bahia. 
FIGURA 1: Localização da APA Serra Branca/Raso da Catarina.

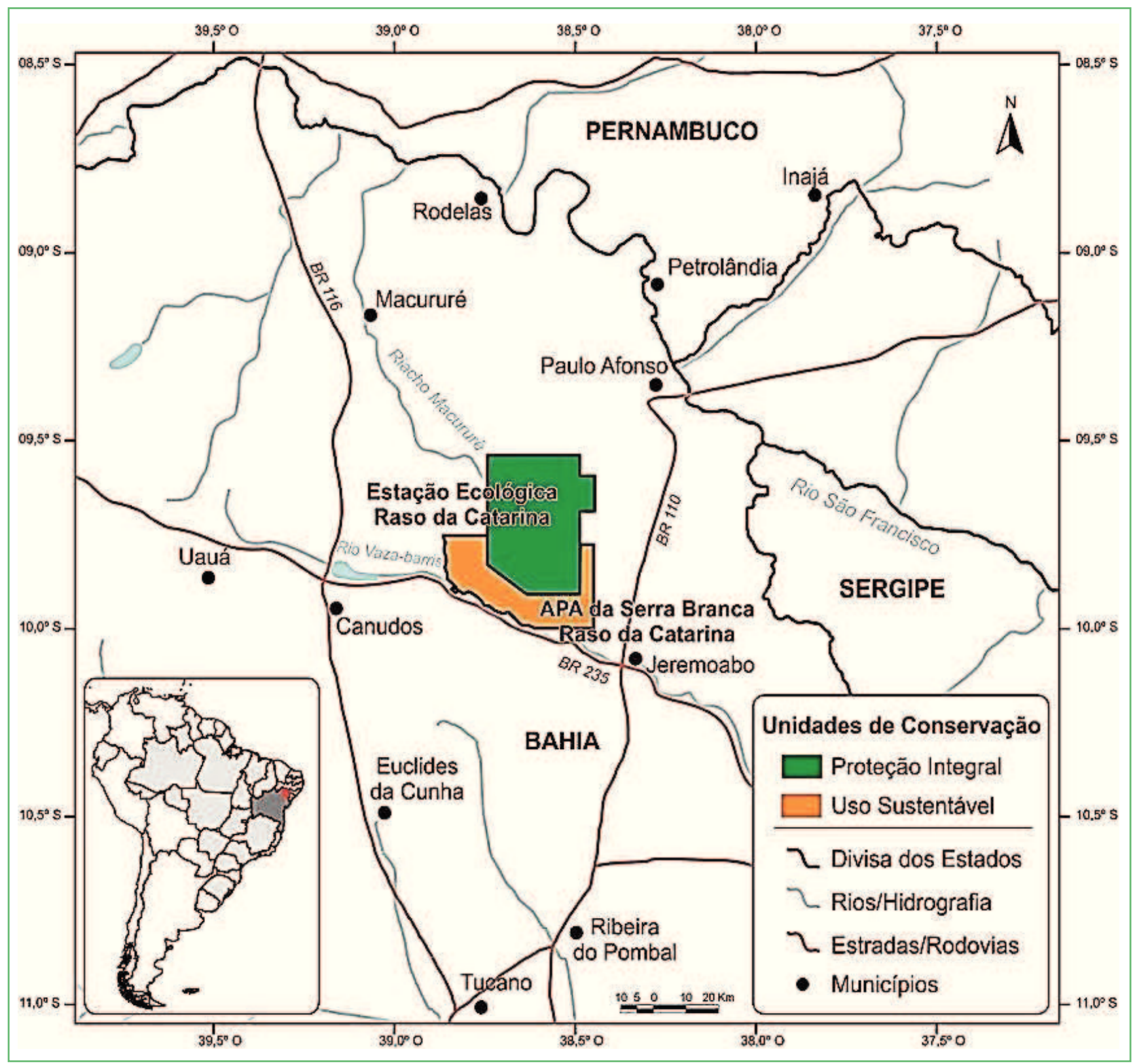

A identificação e descrição do material foram baseadas em bibliografias especializadas (RADFORD et al., 1974; CERVI, 1997; HARRIS; HARRIS, 2001; NUNES; QUEIROZ, 2001; 2006; NUNES, 2002; BERNACCI, 2003; ARAÚJO, 2009), protólogos, imagens de coleções-tipo e consulta às coleções dos herbários visitados: ALCB, HRB, HUEFS e HUNEB
(Acrônimo segundo THIERS, 2015). O tratamento taxonômico inclui chave de identificação para espécies, descrições, ilustrações, dados sobre distribuição geográfica e fenologia. Dados sobre a fenologia são referentes apenas às observações na APA Serra Branca/ Raso da Catarina. 


\section{Resultados e Discussão}

Passifloraceae Juss. ex Roussel, F1. Calvados 2: 334.1806.

Árvores, arbustos ou trepadeiras herbáceas ou lenhosas, com gavinhas axilares. Estípulas presentes, frequentemente decíduas. Folhas alternas, pecioladas, simples ou raramente compostas, frequentemente lobadas, em geral com nectários extraflorais no pecíolo ou lâmina. Inflorescência cimosa ou racemosa, em geral reduzida a uma única flor, vistosa; brácteas $3(-5)$, verticiladas ou alternas, às vezes caducas, nectários presentes ou ausentes. Flores geralmente bissexuadas, actinomorfas; hipanto presente; sépalas (3-)5(-8), geralmente dialissépalo, prefloração imbricada, frequentemente petaloide, nectários presentes ou ausentes; pétalas (3-)5(-8), às vezes ausentes, geralmente dialipétala, prefloração imbricada; corona presente, disposta no ápice do hipanto, formada por um ou mais ciclos de apêndices; opérculo presente, às vezes ausente; límen situado na base do androginóforo, às vezes ausente; androginóforo presente; estames (4-)5(-10), geralmente livres entre si, anteras dorsifixas, rimosas; disco nectarífero geralmente presente ao redor do ovário ou androginóforo; ovário súpero, (2-)3(-5) carpelar; 1-locular, pluriovulado, placentação parietal; estiletes 3-4, geralmente livres entre si; estigmas capitados. Fruto baga indeiscente, raramente cápsula deiscente.

$\mathrm{Na}$ APA Serra Branca/Raso da Catarina, a família está representada pelo gênero Passiflora (Figura 2), com a ocorrência de quatro espécies: $P$. cincinnata Mast., P. foetida L., P. luetzelburgii Harms e P. setacea DC. Todas as espécies estão associadas a solos arenosos com baixa capacidade de retenção de água, sendo geralmente mais resistentes, menos exigentes e, consequentemente, boas colonizadoras. Contudo, as duas primeiras espécies tiveram maior ocorrência, podendo ser encontradas em áreas abertas e ambientes degradados.

\section{Chave de identificação para espécies de Passifloraceae na APA Serra Brancal Raso da Catarina}

1. Plantas com caules pilosos a hirsutos ou vilosos; folhas inteiras, (2-) 3-lobadas ou com lobos laterais, reduzidos, ou inteiras, às vezes no mesmo indivíduo.

2. Estípulas pinatissectas, pilosas, tricomas glandulares presentes; filamentos da corona em cinco séries

2. Passiflora foetida

2'. Estípulas inteiras, lineares, tomentosas ou vilosas, tricomas glandulares ausentes; filamentos da corona em uma ou três séries.

3. Brácteas com margem fortemente serreada a laciniada; sépalas com aristas pouco desenvolvidas, pétalas vermelhococcíneas, filamentos da corona em três séries

3. P. luetzelburgii

3'. Brácteas com margem serrulada; sépalas com aristas muito desenvolvidas; pétalas brancas, filamentos da corona em uma série.

4. P. setacea

1'. Plantas com caules glabros a glabrescentes; folhas (3-) 5-lobadas a (3-) 5-partidas. 1. P. cincinnata

1. Passiflora cincinnata Mast., Gard. Chron. 37: 966.1868. Figuras 2: A; 3: A-E.

Trepadeira herbácea; caule verde, cilíndrico, estriado, totalmente glabro a glabrescente, tricomas glandulares ausentes. Estípulas 6-8 mm compr., inteiras, linearsubuladas, ápice agudo, base simétrica, persistentes, margem serrilhada, glabrescente. Pecíolo 2-3,3 cm compr., glabrescente, 2 glândulas pateliformes, sésseis, verde-escuras, situadas na porção basal a mediana do pecíolo. Folhas cartáceas, discolores; lâmina 4,1-8 × 5,811,5 cm, (3-)5-lobadas a (3-)5-partidas, lobos oblongos a obovais, lobo central ca. 4,1-8 cm, lobos laterais ca. 2,5-4,5 cm compr., ápice mucronado, base cordada, margem serrilhada, 3-5 nervada, reticulada, face abaxial e adaxial glabra, apresentando tricomas esparsos apenas nas nervuras principais. Pedúnculo 4,6-10 cm compr., isolado na axila foliar, glabrescente; brácteas 1,8-3,5 $\times$ 1,4-2,3 cm, verdes, verticiladas, oval-elíptica, ápice agudo, margem serrilhada, pubescentes, glândulas na base e margem, persistentes. Flores solitárias, eretas, 7,5-12,5 cm diâm.; hipanto curto campanulado, ca. 7 mm compr., verde, pubescente; sépalas 2,8-3,7 × 1,3-1,6 $\mathrm{cm}$, face externa verde e face interna violácea, oblongas, 
carnosas, aristadas, aristas pouco desenvolvidas, corniculadas, corno ca. 3,5 mm compr., ápice obtuso, margem lisa, pubescente ou tricomas esparsos apenas nas aristas e cornos, glândulas ausentes; pétalas 3,54,2 × 0,9-1,3 cm, membranáceas, violáceas, oblongas, ápice obtuso; filamentos da corona em várias séries, duas séries externas ca. $5 \mathrm{~cm}$ compr., ápice frisado, violáceos, com faixas rosadas a alvacentas próximas ao meio e arroxeado no ápice, séries intermediárias, filamentos curtos, ca. $1 \mathrm{~cm}$ compr., violáceos, duas séries internas ca. 0,5 cm compr., violáceos; opérculo ca. 1,3 $\mathrm{cm}$ alt., membranoso, margem filamentosa, filamentos ca. $1 \mathrm{~cm}$ alt.; límen ca. $3 \mathrm{~mm}$ alt., cupuliforme, carnoso, envolvendo a base do androginóforo, margem lisa; disco nectarífero presente; androginóforo 1,5-2,8 cm alt., reto; ovário elipsoide a globoso, glabro; 3 estiletes. Baga 3,5-5 $\times$ 3,2-4,5 cm, globosa, verde, glabra; sementes 5-6 × 4 $\mathrm{mm}$, ovais, achatadas, alveoladas.

Material examinado: BRASIL, Bahia: Jeremoabo, Baixa do Estreito, 0959'34,5'S - 38 25'1,5”W, 436 m, A.S.Conceição 1555, 30 Jan. 2009, fl. (HUNEB); Ibidem, Base do ICMBio, Vaca Morta, 0955'17,3"S - 3842’06,0”W, 334 m, J.V.Santos et al. 02, 20 Dez. 2011, fl. (HUNEB); Ibidem, Caminho que vai da ESEC em direção ao povoado Quelés, 0957'12,5'S - 38²6'28,6”W, 519 m, D.D.Vieira et al. 109, 23 Set. 2010, fl. (HUNEB); Ibidem, Estrada principal sentido à ESEC, próximo a Carnaubinha, 0957'3"S -
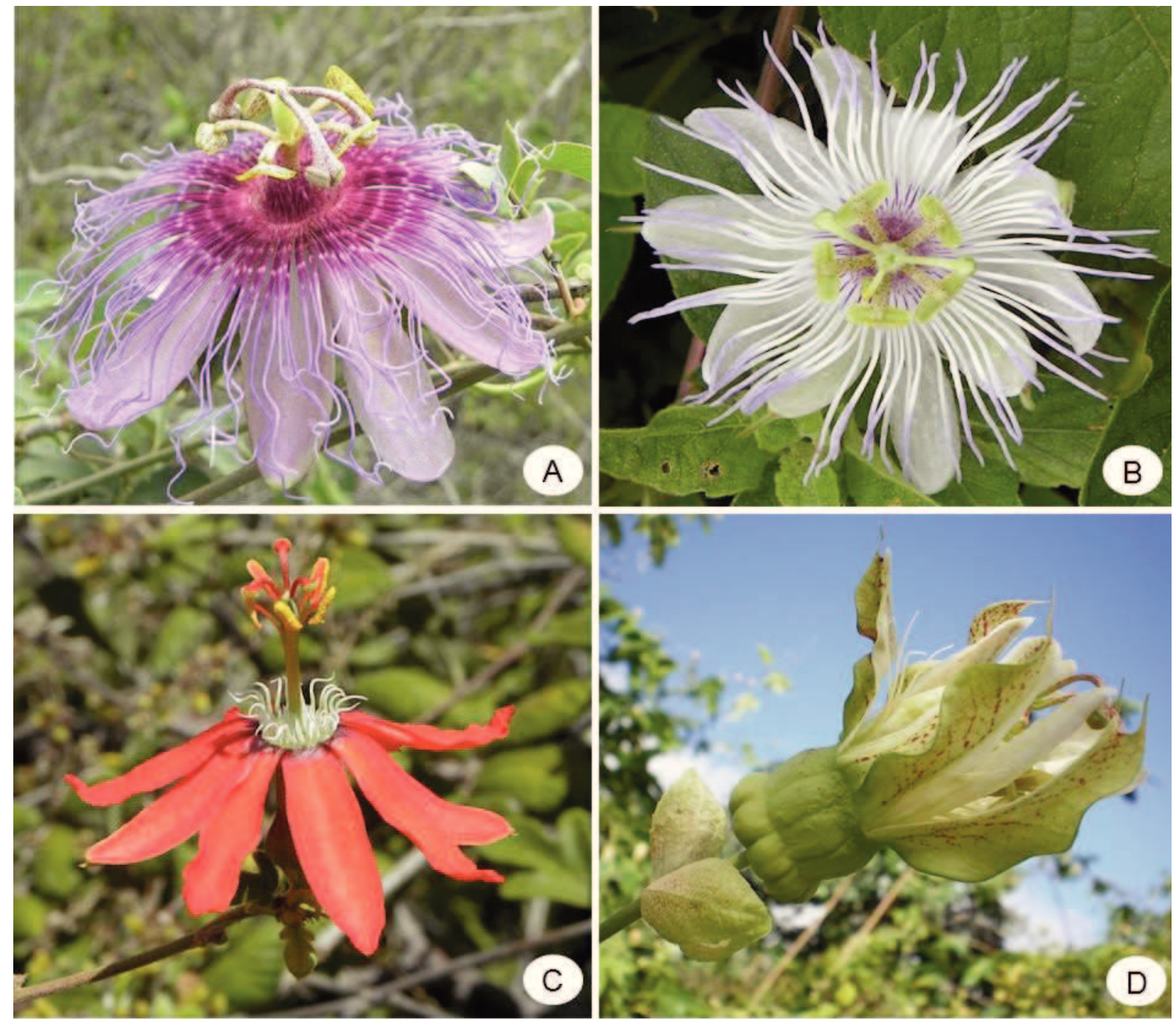
38²6'57'W, 585 m, J.V.Santos et al. 34, 9 Jul. 2012, fl. e fr. (HUNEB); Ibidem, Estrada que dá acesso à Estação Ecológica Raso da Catarina, 0957'12"'S - 38 26'38'W, 523 m, A.S. Conceição 1721, 18.Jun.2009, fl. (HUNEB);

Ibidem, Final da trilha secundária, à estrada principal que vai aos Quelés, 0956'36"S - 38²7'12'W, 551 m, R.R.Varjão 139, 17.Jun.2011, fl. e fr. (HUNEB); Ibidem, Limite Estação Ecológica Raso da Catarina, 0953'43"S - 38²9'33"W, 648 m, A.S.Conceição 1659, 20.Mar.2009, fl. e fr. (HUNEB); Ibidem, Quelés, trilha de acesso à Estação Ecológica Raso da Catarina, 0957'17'S - 38²6'25'W, 575 m, A.S. Conceição 1751, 19.Jun.2009, fl. (HUNEB).

Material adicional: BRASIL, Bahia: Canudos, Estação Biológica de Canudos, 0956'S - 3859'W, R.M.Harley et al. 54891, 17.Fev.2004, fl. (HUEFS); Paulo Afonso, Raso da Catarina, alojamento, 0940'00"S - 38²8'2'W, J.G.C.Sobrinho et al. 552, 11.Ago.2005, fl. e fr. (HUEFS); Ribeira do Pombal, no Tabuleiro, 1050'S - 38³2'W, M.L.Guedes. et al. 10438, 16.Ago.2003, fl. e fr. (ALCB).

Possui ampla distribuição geográfica na América do Sul, ocorrendo desde o Paraguai até a Venezuela, do leste do Brasil ao oeste da Bolívia (KILLIP, 1938). No Brasil, a espécie encontra-se distribuída no Norte (Pará), Nordeste (Alagoas, Bahia, Ceará, Paraíba, Pernambuco, Rio Grande do Norte), Centro-Oeste (Distrito Federal, Goiás, Mato Grosso do Sul e Mato Grosso) e Sudeste (Minas Gerais, São Paulo), em domínios fitogeográficos de Caatinga, Cerrado e Mata Atlântica (BERNACCI et al., 2015). Na Bahia ocorre praticamente em todo o estado, sendo predominante em locais perturbados (NUNES; QUEIROZ, 2006).

Na APA Serra Branca, a espécie pode ser reconhecida pelas folhas 3 a 5-lobadas ou partidas, flores com as pétalas de coloração violácea e pelo maior número de séries de filamentos da corona. $\mathrm{Na}$ área de estudo, foi coletada com flores em janeiro, março, junho, julho, setembro e dezembro, e com frutos em março, junho e julho, sobre solos arenosos e areno-argilosos, com maior ocorrência em áreas abertas e perturbadas. Foram observados visitantes florais tais como abelhas e besouros.
Passiflora cincinnata é potencialmente econômica, utilizada para fins ornamentais, medicinais, apícolas e nutricionais. Seus frutos possuem sementes com polpa mucilaginosa adocicada, utilizada na produção de doces, mousses, sucos e geleias. A espécie também apresenta potencial para uso como porta-enxerto, sendo utilizada em programas de melhoramento genético, devido a sua resistência a patógenos sistêmicos (MELETII et al., 2002; 2005; OLIVEIRA; RUGGIERO, 2005; SAMPAIO et al., 2005; ZUCARELLI, 2007).

2. Passiflora foetida L., Sp. P1. 2: 959. 1753. Figuras 2: B; 3: F-J.

Trepadeira herbácea; caule verde-vináceo, cilíndrico, estriado, piloso a hirsuto, tricomas glandulares estipitados por toda extensão da planta, com odor fétido. Estípulas 4-10 × 3-4 mm comp., pinatissectas, ápice agudo, base simétrica, persistentes, pilosas. Pecíolo 0,6-1,2 cm compr., piloso, glândulas ausentes. Folhas membranáceas, discolores; lâmina 3,4-7,1 × 1,8-5,6 cm, 3-lobada, lobo central ca. 3,4-7,1 cm, lobos laterais ca. 2-4 cm compr., ápice agudo, base cordada, margem serreada, peninérvea, face abaxial e margem pilosa, face adaxial pilosa. Pedúnculo 2-3 cm compr., isolado na axila foliar, piloso; brácteas 2,4-3,1 × 1,2 cm, verdes, verticiladas, pinatissectas, pilosas, glândulas ausentes, persistentes. Flores solitárias eretas, ca. $5 \mathrm{~cm}$ diâm.; hipanto curto campanulado, ca. $3 \mathrm{~mm}$ compr., esverdeado, piloso; sépalas ca. $2 \times 0,6 \mathrm{~cm}$, face externa verde-claro, pilosa e face interna branca, oblongas, corniculadas, corno 5-6 mm compr., com glândula no ápice, ápice agudo, margem lisa, glândulas ausentes; pétalas $1,7 \times 0,6 \mathrm{~cm}$, membranáceas, branca-esverdeadas, oblongas, ápice obtuso; filamentos da corona em 5 séries, série externas ca. $1,5 \mathrm{~cm}$ compr., filiformes, brancos com base roxaazulada, séries internas ca. $2 \mathrm{~mm}$ compr., filiformes, roxos a azulados; opérculo ca. $2 \mathrm{~mm}$ alt., membranoso, margem denteada; límen ca. $3 \mathrm{~mm}$ alt., membranoso, envolvendo a base do androginóforo, margem lisa; disco nectarífero presente; androginóforo ca. $1 \mathrm{~cm}$ alt., reto; ovário globoso, densamente piloso; 3 estiletes. Baga 1,5-2,9 $\times 1,6-2,6 \mathrm{~cm}$, globosa, verde, pilosa; sementes 4-6 $\times$ 2-3 mm, oblongas, achatadas, alveoladas.

Material examinado: BRASIL, Bahia: Jeremoabo, Base do ICMBio, Vaca Morta, 0955'17,3"S - 
$38^{\circ} 42^{\prime} 06,0$ 'W, 334 m, J.V.Santos et al. 03, 20.Dez.2011, fl. e fr. (HUNEB); Ibidem, Entrada da APA, próximo à porteira, 09 $57^{\prime} 30,1^{\prime \prime} \mathrm{S}-38^{\circ} 26^{\prime} 19,3$ ' $\mathrm{W}, 524 \mathrm{~m}$, R.R.Varjão 57, 08.Abr.2011, fl. (HUNEB); Ibidem, Entrada da Roça Velha, Baixa dos Mandacarus, próximo ao açude, 0952'57'S - 3840'0,4'W, 440 m, J.V.Santos et al. 06, 27.Mar.2012, fr. (HUNEB); Ibidem, Estrada saindo dos Quelés, sentido à ESEC, 0957'39"S 38²6'18'W, 497 m, J.B.Lima et al. 31, 9.Jun.2012, fl. (HUNEB); Ibidem, Trilha da Vaca Morta, 0954'59,2”S - 3841'54”'W, 363 m, L.R. Silva et al. 55, 04.Jan.2011, fl. (HUNEB); Ibidem, Vaca Morta, 09'52'23,9"S 38³8'24,8”'W, 496 m, M.V.Romão 266, 22.Ago.2008, fl. e fr. (HUNEB); Ibidem, Vaca Morta, a $100 \mathrm{~m}$ da base do ICMBio, 0955'17,3”S - 3842'06,0”W, 334 m, J.V.Santos et al. 35, 10.Jul.2012, fl. (HUNEB).

Material adicional: BRASIL, Bahia: Canudos, Base I, Biodiversitas, entrada da Gruta do Minadouro, 09'56'51"'S - 38 59'25”W, 388 m, A.A. de Oliveira et al. 168, 22.Mai.2003, fl. e fr. (HUEFS); Glória, Brejo do Burgo, Baixa de Fontana, 09 $20^{\prime} \mathrm{S}-38^{\circ} 18^{\prime} \mathrm{W}$, M.V.Morais 612, 9.Mar.2004, fl. (HUEFS); Euclides da Cunha, Sítio do Jaime, 10³0’00”S - 3900'00”W, M.L.Guedes et al. 11465, 21.Mar.2004, fr. (ALCB); Paulo Afonso, Reserva Ecológica Raso da Catarina, 09'39'05"S - 38²4'00"W, 454 m, A. O. Moares et al. 85, 1.Dez.2005, fl. e fr. (HUEFS); Ribeira do Pombal, Tabuleiro, 1050' - 38 $32^{\circ}$ 'W, M.L. Guedes et al. 10438, 16.Ago.2003, fl. e fr. (ALCB); Santa Brígida, Quarenta, J.S.Silva 647, 23.Mai.1978, fl. (HUEFS); Tucano, povoado Bizamum, ca. $23 \mathrm{~km}$ de Tucano, 1052'43"S 38 59'40”W, 241 m, D. Cardoso et al. 102, 23.Jun.2004, fl. e fr. (HUEFS).

Apresenta ampla distribuição geográfica na América do Sul, com ocorrência também em Porto Rico, Jamaica e Antilhas (KILLIP, 1938). A espécie é bem distribuída no Brasil, registrada praticamente em todos os estados e tipos vegetacionais como Amazônia, Caatinga, Cerrado, Mata Atlântica, Pampa e Pantanal (NUNES; QUEIROZ, 2006; BERNACCI et al., 2015).

Passiflora foetida L. diferencia-se das outras espécies registradas na área de estudo por possuir tricomas glandulares com odor fétido, estípulas e brácteas pinatissectas, e flores com filamentos da corona em cinco séries.

É uma espécie predominante na APA, sendo encontrada geralmente em locais perturbados ou degradados, como beira de estradas e habitações. Foi coletada com flores em janeiro, abril, junho, julho, agosto e dezembro, e com frutos nos meses de março, agosto e dezembro, sobre solos arenosos e areno-argilosos. Foram observados visitantes florais como formigas e moscas.

A espécie apresenta características que podem ser introduzidas em maracujazeiro comercial, tais como resistência a doenças e pragas e autocompatibilidade (JUNQUEIRA et al., 2005; MELETII et al., 2005; MOANASUNDARI et al., 2007), e possui também potencial frutífero (SAMPAIO et al., 2005).

3. Passiflora luetzelburgii Harms, Repert. Spec. Nov. Regni Veg. 19: 32. 1923. Figuras 2: C; 4: A-E.

Trepadeira lenhosa; caule cilíndrico, estriado, viloso, com tricomas brancos, tricomas glandulares ausentes. Estípulas 2-4 mm compr., inteiras, lineares, ápice agudo, base simétrica, persistentes, tomentosas. Pecíolo 3-6 mm compr., tomentoso, 2 glândulas sésseis, marrons, situadas na porção mediano-basal. Folhas cartáceas a semi-coriáceas, discolores; lâmina 3-6,4 $\times$ 1,3-5 cm, 3-lobada ou com lobos laterais reduzidos ou inteira, às vezes no mesmo indivíduo, oblonga a oval; ápice obtuso, truncado a emarginado, base obtusa a subcordada, margem levemente crenada, revoluta, nervação peninérvea, reticulada, face abaxial tomentosa e face adaxial vilosa, lobo central ca. 3-4,8 cm, lobos laterais ca. 1,7-3,8 cm compr., ápice obtuso a agudo. Pedúnculo 0,9-2,5 cm compr., isolado na axila foliar, tomentoso; brácteas 5-10 × 3-6 mm, verdes, verticiladas, elíptica-lanceolada, ápice agudo, corniculado, margem fortemente serreada a laciniadas, vilosas, glândulas ausentes, persistentes. Flores solitárias eretas, 3-5,5 cm diâm.; hipanto longo, tubular levemente dilatado na base, 1,2-1,8 cm compr., vináceo com base esverdeada, glabro; sépalas 2-2,8 × 0,5-0,8 cm, vermelhas, oblongolanceoladas, aristadas, aristas pouco desenvolvidas, corniculadas, corno ca. $2 \mathrm{~mm}$ compr., ápice obtuso, margem lisa, poucos tricomas esparsos perto do corno, glândulas ausentes; pétalas 1,9-2,4 × 0,5 cm, membranáceas, vermelho-coccíneas, oblongas, ápice 
FIGURA 3: A-E. P. cincinnata: A. Ramo reprodutivo. B. Detalhe do caule. C. Bráctea. D. Detalhe das sépalas no botão floral. E. Flor em corte transversal (Varjão 139). F-J. P. foetida: F. Ramo reprodutivo. G. Detalhe do caule. H. Bráctea. I. Detalhe das sépalas no botão floral. J. Flor em corte transversal (Silva 55).

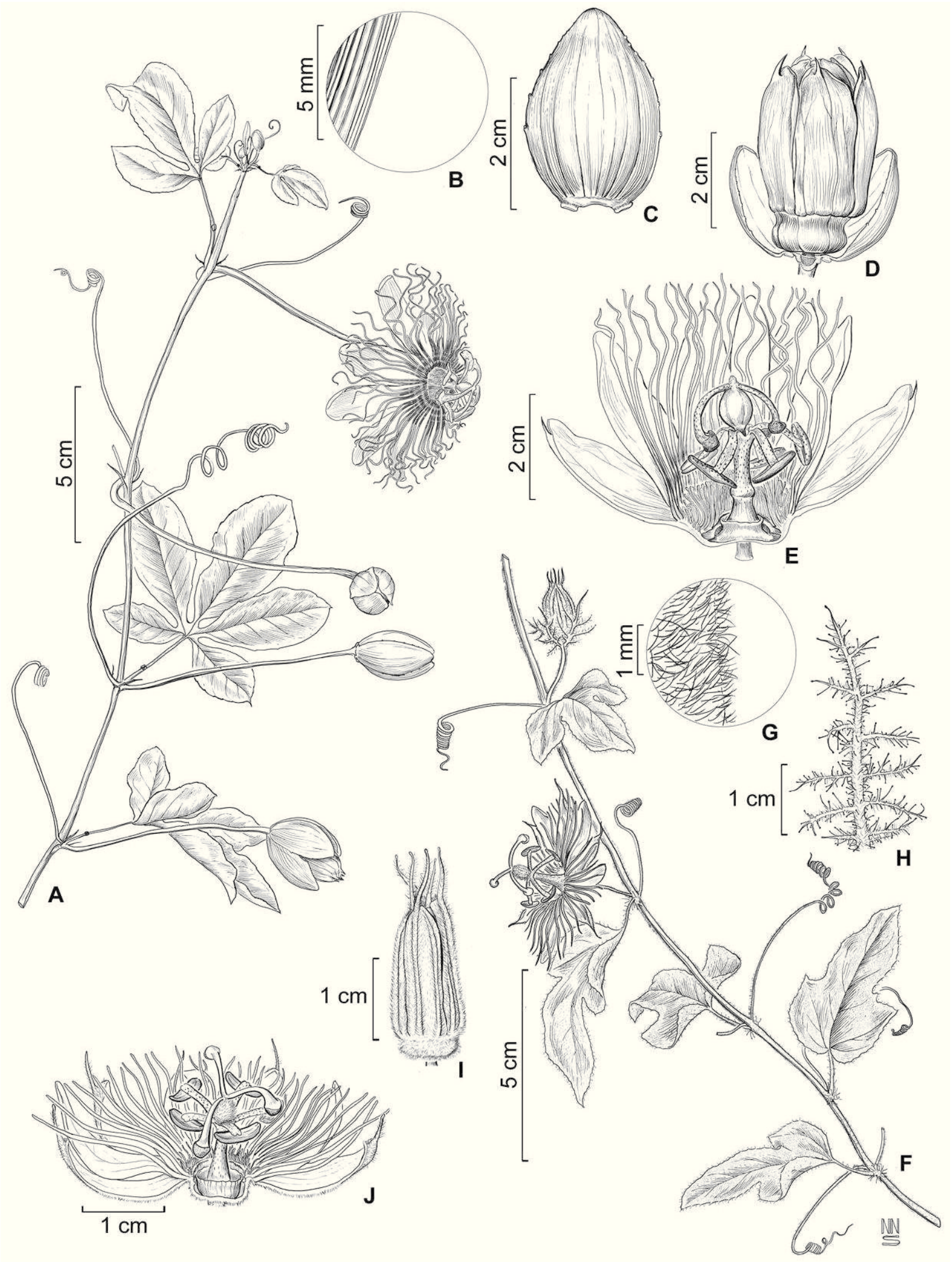


agudo a obtuso; filamentos da corona em 3 séries, série externa ca. 1,5 mm compr., série intermediária ca. 3 $\mathrm{mm}$ compr. e série interna ca. $6 \mathrm{~mm}$ compr., filiformes, brancos; opérculo ca. $3 \mathrm{~mm}$ alt., membranoso, ereto, filiforme; límen ca. $4 \mathrm{~mm}$ alt., anular, envolvendo a base do androginóforo, membranoso, margem denticulada; disco nectarífero presente; androginóforo $2-3 \mathrm{~cm}$ alt., reto; ovário elipsoide, 3-anguloso, glabro; 3 estiletes. Baga 3,5-4 × 2,5 cm, ovoide, verde, glabra; sementes ca. $7 \times 4 \mathrm{~mm}$, ovadas, achatadas, alveoladas.

Material examinado: BRASIL, Bahia: Jeremoabo, Areia Branca, cabeceira da Baixa Grande sentido Arapuá, 09'58'37'S - 38 27'48,5”W, 627 m, A.S.Conceição 1595, 19 Mar. 2009, fl. (HUNEB); Ibidem, Caminho da ESEC em direção ao povoado Quelés, 0956'13"S - 38 28'21”'W, 633 m, D.D.Vieira 48, 08 Dez. 2009, fl. (HUNEB); Ibidem, Estrada secundária que sai do povoado Quelés em direção à ESEC, 0956’36,6”S 38²7'27,2'W, 558 m, J.V.Santos et al. 43, 11 Jul. 2012, fl. (HUNEB); Ibidem, Fazenda Logradouro próximo ao limite da Estação Ecológica Raso da Catarina, 09'55'02"S - 38 29'35”W, 664 m, A.S.Conceição 1617, 20 Mar. 2009, fl. e fr. (HUNEB); Ibidem, Trilha secundária da estrada que sai do povoado Quelés em direção a ESEC, 0956'37,1”S - 38²7'26,6”W, 603 m, J.V.Santos et al. 04, 26 Mar. 2012, fl. (HUNEB).

Material adicional: BRASIL, Bahia: Canudos, Estação Biológica de Canudos, Toca Velha (sede da Biodiversitas), 1001'58'S - 3909'00"W, L.P de Queiroz et al. 7031, 29 Out. 2001, fl. (HUEFS); Glória, BA-210 sentido Glória-Rodelas, ca. de $3,5 \mathrm{~km}$ do Centro Administrativo José Messias, 09¹3'53"S - 38²4'29"W, 310 m, A.S. Conceição et al. 973, 7.Jun.2007, fl. (HUEFS); Paulo Afonso, Reserva Ecológica do Raso da Catarina, próximo à Mata Pororoca, L.P. de Queiroz 459, 08 Dez. 1982, fl. (ALCB); Santa Brígida, fazenda do Sr. José Alves,

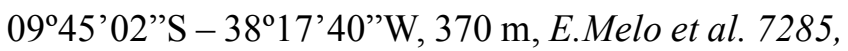
28 Nov. 2009, fl. e fr. (ALCB); Ribeira do Pombal, 1 $\mathrm{km}$ ao Oeste do Povoado de Tapera, $10^{\circ} 50^{\prime} \mathrm{S}-38^{\circ} 33^{\prime} \mathrm{W}$, L.R.Noblick 2968, 01 Mar. 1984, fl. e fr. (HRB); Tucano, povoado Pedra Grande, na estrada para a

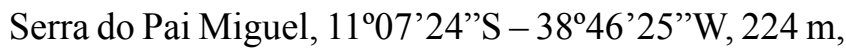
D. Cardoso et al. 2228, 20 dez. 2007, fl. e fr. (HUEFS).
Espécie endêmica do Nordeste semiárido do Brasil, sendo encontrada apenas nos estados da Bahia, Pernambuco e Piauí (NUNES; QUEIROZ, 2006; ARAÚJO, 2009), em ambientes de Caatinga e Cerrado (BERNACCI et al., 2015). Nos períodos mais secos, geralmente de setembro a fevereiro, apresenta marcada caducifolia, permanecendo apenas as folhas que estão mais próximas à porção apical dos ramos.

Passiflora luetzelburgii Harms pode ser confundida com Passiflora setacea DC. pelo formato das folhas, 3-lobada ou com lobos laterais reduzidos ou inteira, às vezes no mesmo indivíduo, podendo ser diferenciada por possuir folhas com a face adaxial tomentosa ( $v s$. glabra) e pétalas vermelhas ( $v s$. branca). $\mathrm{Na}$ área de estudo, foi coletada com flores em março, julho e dezembro, e com frutos apenas no mês de março, em áreas mais preservadas com Caatinga arbustiva, associadas aos solos areno-argilosos. Foram observadas borboletas como visitantes florais.

A espécie possui potencial frutífero, apícola (SAMPAIO et al., 2005) e ornamental, principalmente pela beleza e delicadeza de suas flores.

4. Passiflora setacea DC., Prodr. 3: 329.1828. Figuras 2: D; 4: F-J.

Trepadeira herbácea; caule verde, cilíndrico, estriado, viloso, tricomas glandulares ausentes. Estípulas ca. $3 \mathrm{~mm}$ compr., inteiras, lineares, ápice agudo, base simétrica, caducas, vilosas. Pecíolo 1,3-2,3 cm compr., viloso, glândulas, 1 a 2 glândulas pateliformes, sésseis, verde-escuras, situadas nas porções basal, mediana e apical do pecíolo. Folhas cartáceas, discolores; lâmina 4,9-10,1 × 3,7-10,8 cm, 2-3 lobada ou inteira, às vezes no mesmo indivíduo, lobo central ca. 4,9-10,1 cm, lobos laterais ca. 2-6 cm compr., ápice agudo a acuminado, base cordada, margem serrulada, revoluta, 3-nervada, reticulada, face abaxial apresentando tricomas vilosos apenas nas nervuras principais e tricomas esparsos nas demais nervuras, face adaxial rugosa, glabra. Pedúnculo 6-18 cm compr., isolado na axila foliar, viloso; brácteas 1,5-2 × 1,1-1,7 cm, verde-claras, com manchas vináceas, verticiladas, oval-elípticas, ápice agudo, mucronado, margem serrulada, com tricomas nas nervuras, glândulas na margem, persistentes. Flores solitárias eretas, 4-5 
FIGURA 4: A-E. P. luetzelburgii: A. Ramo florífero. B. Detalhe do caule. C. Bráctea. D. Detalhe das sépalas no botão floral. E. Flor em corte transversal (Santos 43). F-J. P. setacea: F. Ramo reprodutivo. G. Detalhe do caule. H. Bráctea. I. Detalhe das sépalas no botão floral. J. Flor em corte transversal (Santos 42).
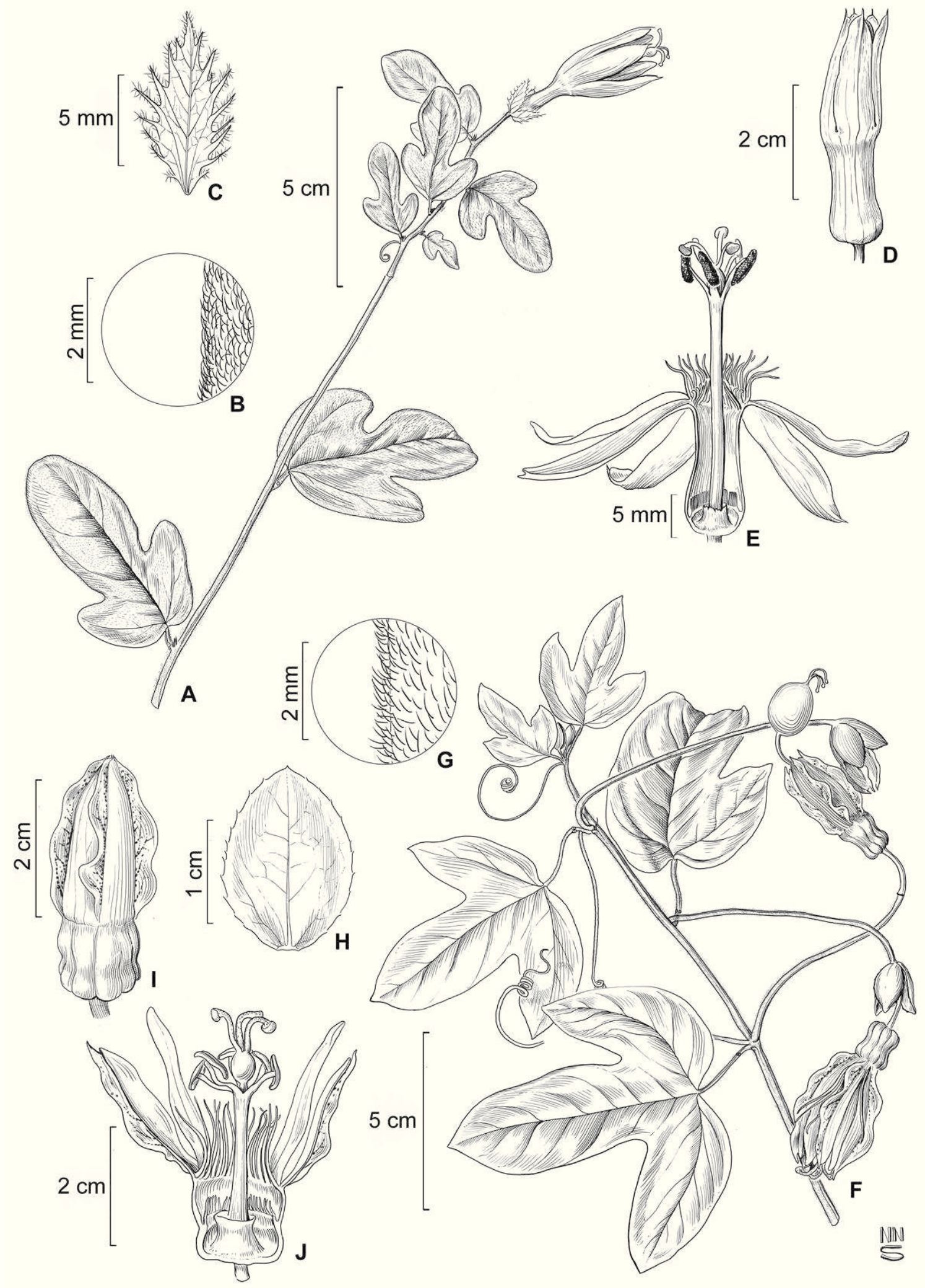
cm diâm.; hipanto longo, cilíndrico-campanulado com base dilatada, 1-1,5 × 1-1,7 cm compr., verde-claro com manchas vináceas, mais escuras que as demais, glabro; sépalas 2,5-3 × 0,5-0,8 cm, face externa verde pintalgadas com manchas vináceas, face interna branca, oblonga-lanceoladas, aladas e aristadas, aristas muito desenvolvidas, tricomas esparsos nas aristas, corniculadas, corno 4-6 mm compr., ápice agudo, margem lisa, glândulas ausentes; pétalas 2,5-2,8 × 0,5$0,7 \mathrm{~cm}$, membranáceas, brancas, linear-oblongas, ápice agudo; filamentos da corona em 1 série, $1,1-1,4 \mathrm{~cm}$, filiformes, brancos com base esverdeada; opérculo 4-5 $\mathrm{mm}$ alt., membranoso, tubular, filiforme; límen ca. 4 $\mathrm{mm}$ alt., anular cupuliforme, membranoso, envolvendo a base do androginóforo, margem lisa; disco nectarífero presente; androginóforo 2,5- $3 \mathrm{~cm}$ alt., reto; ovário elipsoide a globoso, glabro; 3 estiletes. Baga ca. 4,4 $\times$ $4,2 \mathrm{~cm}$, elipsoide, verde, glabra; sementes ca. $5 \times 3-3,5$ $\mathrm{mm}$, obovais, achatadas, alveoladas.

Material examinado: BRASIL, Bahia: Jeremoabo, Baixa Grande próximo ao Povoado Quelés, 0958'30,5”S - 38 27'0,02”W, 569 m, A.S.Conceição 1594, 19 Mar. 2009, fl. e fr. (HUNEB); Ibidem, Baixa Grande sentido Tamborí, 0958'26”S - 38²6'57'W, 527 m, A.S.Conceição 1607, 20 Mar. 2009, fl. e fr. (HUNEB); Ibidem, Estrada que vai da ESEC em direção ao povoado Quelés, 0956'36,1"S $38^{\circ} 27^{\prime} 12,1$ 'W, 551 m, D.D.Vieira 105, 23 Set. 2010, fl. (HUNEB); Ibidem, Estrada secundária que sai do povoado Quelés em direção à ESEC, 0956'36,6"S - 38 $27^{\circ} 27,2$ 'W, 558 m, J.V.Santos et al. 42, $11 \mathrm{Jul}$. 2012, fl. (HUNEB); Ibidem, Trilha secundária da estrada que sai do povoado Quelés em direção à ESEC, 0956’37,1'S - 38²7'26,6”W, 603 m, J.V.Santos et al. 05, 26 Mar. 2012, fl. e fr. (HUNEB).

Material adicional: BRASIL, Bahia: Caetité, estrada

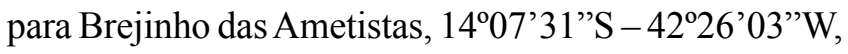
726 m, C.Correia et al. 36, 29 Abr. 2001, fl. e fr. (HUEFS); Jequié, km 40 da estrada Jequié/Contendas do Sincorá, A.M. de Carvalho et al. 2002, 12 Out. 1983, fl. (HRB); Lençois, $107 \mathrm{~km}$ de Itaberaba, à margem da

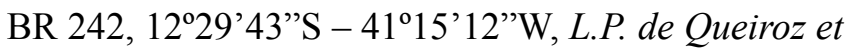
al. 2005, 31 Out. 1987, fl. (HRB).
Passiflora setacea DC. é endêmica do Brasil, encontrada apenas no Nordeste (Bahia), Centro-Oeste (Distrito Federal, Goiás, Mato Grosso) e Sudeste (Espírito Santo, Minas Gerais, Rio de Janeiro), em ambientes de Caatinga, Cerrado e Mata Atlântica (BERNACCI et al., 2015).

A espécie pode ser reconhecida na área de estudo pelas sépalas aladas, com aristas muito desenvolvidas pintalgadas com manchas vináceas e corona apresentando uma única série de filamentos. Foi coletada com flores nos meses de março, julho e setembro, e com frutos apenas em março, em locais mais preservados, sobre solos areno-argilosos.

Passiflora setacea apresenta potencial econômico: apícola, medicinal, frutífero, paisagístico e alimentício, através da utilização da polpa mucilaginosa presente nas sementes, que servem para a produção de sucos e sorvetes. A espécie também pode ser utilizada em programas de melhoramento genético como portaenxerto, por ser resistente a diversos patógenos (MENEZES et al., 1994; JUNQUEIRA et al., 2005; MELETII et al., 2005; SAMPAIO et al., 2005; PEREIRA et al., 2007; 2008; ARAÚJO, 2009).

\section{Agradecimentos}

Agradecemos à Fundação de Apoio à Pesquisa do Estado da Bahia (FAPESB, PET 0023/2007) e ao Conselho Nacional de Desenvolvimento Científico e Tecnológico (CNPq Proc. 552589/2011-0), pelo apoio financeiro ao projeto. À Companhia Hidro Elétrica do São Francisco (CHESF), o suporte nos trabalhos de campo. Aos assessores $a d$ hoc as valiosas sugestões. A primeira autora agradece também ao $\mathrm{CNPq}$, a concessão de bolsa de Iniciação Científica (Proc. 161383/2011-4). Aos curadores e técnicos dos herbários visitados, a prontidão durante a consulta das coleções. Ao Natanael Santos, as ilustrações botânicas.

\section{Referências}

ARAÚJO, D. A. Passifloraceae. In: ALVES, M.; ARAÚJO, M. F.; MACIEL, J. R.; MARTINS, S. (Ed.). Flora de Mirandiba. Recife: Associação Plantas do Nordeste, 2009. p. 280-282. 
BERNACCI, L. C. Passifloraceae. In: WANDERLEY, M. G. L.; SHEPPERD, G. J.; MELHEM, T. S.; GIULIETTI, A. M.; KIRIZAWA, M. (Ed.). Flora fanerogâmica do estado de São Paulo. Vol. 3. São Paulo: RIMA/FAPESP, 2003. p. 247-274.

BERNACCI, L. C.; CERVI, A. C.; MILWARD-DE-AZEVEDO, M. A.; NUNES, T. S.; IMIG, D. C.; MEZZONATO, A. C. Passifloraceae. In: FORZZA, R. C.; STEHMANN, J. C.; NADRUZ, M.; COSTA, A.; CARVALHO JR., A.; PEIXOTO, A. L.; WALTER, B. M. T.; BICUDO, C.; MOURA, C. W. N.; ZAPPI, D.; COSTA, D. P.; LLERAS, E.; MARTINELLI, G.; LIMA, H. C.; PRADO, J.; BAUMGRATZ, J. F. A.; PIRANI, J. R.; SYLVESTRE, L. S; MAIA, L. C.; LOHMANN, L. G.; PAGANUCCI, L.; ALVES, M. V. S.; SILVEIRA, M.; MAMEDE, M. C. H.; BASTOS, M. N. C.; MORIM, M. P.; BARBOSA, M. R.; MENEZES, M.; HOPKINS, M.; EVANGELISTA, P. H. L.; GOLDENBERG, R.; SECCO, R.; RODRIGUES, R. S.; CAVALCANTI, T.; SOUZA, V. C. Lista de espécies da flora do Brasil. 2015. Rio de Janeiro: Jardim Botânico do Rio de Janeiro. Disponível em: <http://floradobrasil.jbrj.gov.br/ jabot/floradobrasil/FB182>. Acesso em: 23 mar. 2015.

CERVI, A. C. Passifloraceae do Brasil: estudo do gênero Passiflora L., subgênero Passiflora. Fontqueria, Madrid, v. 45, p. 1-923, 1997.

CERVI, A. C. Estudo das passifloras brasileiras: o subgênero Dysosmioides Killip do gênero Passiflora L. para o Brasil. Estudos de Biologia, Curitiba, v. 45, p. 91-115, 2000.

CERVI, A. C.; DUNAISKI JUNIOR, A. Passifloraceae do Brasil: estudo do gênero Passiflora L. subgênero Distephana (Juss.) Killip. Estudos de Biologia, Curitiba, v. 26, n. 55, p. 45-67, 2004.

CERVI, A. C.; LINSINGEN, L. V. Sinopse taxonômica das Passifloraceae Juss. no complexo de cerrado (savana) no estado do Paraná - Brasil. Iheringia, Série Botânica, Porto Alegre, v. 63, n. 1, p. 145-157, 2008.

COSTA, E. C. S.; NUNES, T. S.; MELO, J. I. M. Flora da Paraíba, Brasil: Passifloraceae sensu stricto. Rodriguésia, Rio de Janeiro, v. 66, n. 1, p. 271-284, 2015.

DE CANDOLLE, A. P. Passifloraceae. In: DE CANDOLLE, A. P. (Ed). Prodromus systematis naturalis Regni Vegetabilis. Paris: Treuttel et Wurtz, 1828. p. 321-338.

FARINAZZO, N. M.; SALIMENA, F. R. G. Passifloraceae na Reserva Biológica na Represa do Grama, Descoberto, Minas Gerais, Brasil. Rodriguésia, Rio de Janeiro, v. 58, n. 4, p. 823-833, 2007.

FEUILlET, C.; MACDOUGAL, J. M. A New infrageneric classification of Passiflora L. (Passifloraceae). Passiflora, Surrey, v. 13, p. 34-38, 2003 [2004].

FEUILleT, C.; MACDOUGAL, J. M. Passifloraceae. In: KUBITZKI, K. (Ed.). The families and genera of vascular plants. Vol. 9. Berlin: Springer, 2007. p. 270-281.

FOSBERG, F. R.; SACHET, M. H. Manual for tropical herbaria. Utrecht: International Bureau for Plant Taxonomy and Nomenclature 1965. $132 \mathrm{p}$.

HARRIS, J. G.; HARRIS M. W. Plant identification terminology: an illustrated glossary. Spring Lake: Spring Lake Publishing, 2001. $206 \mathrm{p}$.

JUDD, W. S.; CAMPBELL, C. S.; KELLOGG, E. A.; STEVENS, P. F.; DONOGHUE, M. J. Sistemática Vegetal: um enfoque filogenético. 3. ed. Porto Alegre: Artmed, 2009. 632 p.
JUNQUEIRA, N. T. V.; BRAGA, M. F.; FALEIRO, F. G.; PEIXOTO, J. R.; BERNACCI, L. C. Potencial de espécies silvestres de maracujazeiro como fonte de resistência a doenças. In: FALEIRO, F. G.; JUNQUEIRA, N. T. V.; BRAGA, M. F. (Ed.). Maracujá: germoplasma e melhoramento genético. Planaltina: Embrapa Cerrados, 2005. p. 81-108.

KILLIP, E. P. The American species of Passifloraceae. Publications Field Museum of Natural History, Botanical Series, Chicago, v. 19, n. 1-2, p. 1-613, 1938.

KROSNICK, S. E.; FORD, A. J.; FREUDENSTEIN, J. V. Taxonomic revision of Passiflora subgenus Tetrapathea including the monotypic genera Hollrungia and Tetrapathea (Passifloraceae), and a new species of Passiflora. Systematic Botany, Laramie, v. 34, p. 375-385, 2009.

LINNAEUS, C. Species plantarum. Vol. 2. Holmiae: Laurentii Salvii, 1753. $673 \mathrm{p}$

MASTERS, M. T. Passifloraceae. In: MARTIUS, C. F. P.; EICHLER, A. W.; URBAN, I. (Ed.). Flora Brasiliensis. Munchen, Wien, Leipzig, 1872. p. 529-628.

MELETII, L. M. M.; FURLANI, P. R.; ÁLVARES, V.; SOARESSCOTT, M. D.; BERNACCI, L. C.; FILHO, J. A. A. Novas tecnologias melhoram a propagação de mudas de maracujá. Campinas. O Agronômico, Campinas, v. 54, n. 1, p. 30-33, 2002.

MELETII, L. M. M.; SOARES-SCOTT, M. D.; BERNACCI, L. C.; PASSOS, I. R. S. Melhoramento genético do maracujá: passado e futuro. In: FALEIRO, F. G.; JUNQUEIRA, N. T. V.; BRAGA, M. F. (Ed.). Maracujá: germoplasma e melhoramento genético. Planaltina: Embrapa Cerrados, 2005. p. 55-78.

MENEZES, J. M. T.; OLIVEIRA, J. C.; RUGGIERO, C.; BANZATO, D. A. Avaliação da taxa de pegamento de enxertos de maracujá amarelo sobre espécies tolerantes à "morte prematura de plantas”. Científica, Jaboticabal, v. 22, p. 95-104, 1994.

MILWARD-DE-AZEVEDO, M. A. Passifloraceae do Parque Estadual de Ibitipoca, Minas Gerais. Boletim de Botânica da Universidade de São Paulo, São Paulo, v. 25, n. 1, p. 71-79, 2007. MILWARD-DE-AZEVEDO, M. A.; BAUMGRATZ, J. F. A. Passiflora L. subgênero Decaloba (DC.) Rchb. (Passifloraceae) na Região Sudeste do Brasil. Rodriguésia, Rio de Janeiro, v. 55, n. 85, p. $17-54,2004$.

MILWARD-DE-AZEVEDO, M. A; VALENTE, M. C. Passifloraceae da Mata de Encosta do Jardim Botânico do Rio de Janeiro e Arredores, Rio de Janeiro, RJ. Arquivos do Museu Nacional, Rio de Janeiro, v. 62, n. 4, p. 367-374, 2004.

MOANASUNDARI, C.; NATARAJAN, D.; SRINIVASAN, K., UMA-MAHESWARI, S.; RAMACHANDRAN, A. Antibacterial properties of Passiflora foetida L. - A common exotic medicinal plant. African Journal of Biotechnology, Cape Town, v. 6, n. 23, p. 2650-2653, 2007.

MORI, S. A.; SILVA, L. A. M.; LISBOA, G.; CORADIN, L. Manual de manejo de herbário fanerogâmico. Itabuna: Centro de Pesquisas do Cacau, 1989. 103 p.

NUNES, T. S. A família Passifloraceae no estado da Bahia, Brasil. 2002. 190 f. Dissertação (Mestrado em Botânica) Universidade Estadual de Feira de Santana, Feira de Santana. 2002.

NUNES, T. S. Estudos Sistemáticos em Passiflora L. subgênero Deidamioides (Harms) Killip (Passifloraceae). 2009. 213 f. Tese (Doutorado em Botânica) - Universidade Estadual de Feira de Santana, Feira de Santana. 2009. 
NUNES, T. S.; QUEIROZ, L. P. A Família Passifloraceae na Chapada Diamantina, Bahia, Brasil. Sitientibus, Série Ciências Biológicas, Feira de Santana, v. 1, n. 1, p. 33-46, 2001.

NUNES, T. S.; QUEIROZ, L. P. Flora da Bahia: Passifloraceae. Sitientibus, Série Ciências Biológicas, Feira de Santana, v. 6, n. 3, p. 194-226, 2006.

OLIVEIRA, J. C.; RUGGIERO, C. Espécies de maracujá com potencial agronômico. In: FALEIRO, F. G.; JUNQUEIRA, N. T. V.; BRAGA, M. F. (Ed.). Maracujá: germoplasma e melhoramento genético. Planaltina: Embrapa Cerrados, 2005. p. 141-158.

PEREIRA, W. V. S.; VIEIRA, L. M.; REIS, S. B.; NEVES, S. C.; MERCANTENTE-SIMÕES, M. O.; RIBEIRO, L. M. Avaliação histoquímica de folhas de Passiflora setacea DC. (Passifloraceae). In: SIMPÓSIO INTERNACIONAL DE SAVANAS TROPICAIS, 2, 2008, Brasília. Simpósio... Brasília, 2008. p. 1-6.

PEREIRA, W. V. S.; VIEIRA, L. M.; RIBEIRO, L. M.; MERCANTENTE-SIMÕES, M. O Efeito do substrato na germinação e desenvolvimento inicial de Passiflora setacea D.C. In: CONGRESSO NACIONAL DE ECOLOGIA DO BRASIL, IX, 2007, Caxambu. Anais... Caxambu: SEB, 2007. p. 1-2.

PESSOA, S. V. A. Passifloraceae. In: LIMA, M. P. M.; GUEDESBRUNI, R. R. (Org.). Reserva Ecológica de Macaé de Cima, Nova Friburgo - RJ: aspectos florísticos das espécies vasculares. Vol. 1. Rio de Janeiro: Jardim Botânico do Rio de Janeiro, 1994. p. 315-322.

RADFORD, A. E.; DICKINSON, W. C.; MASSEY, J. R.; BELL, C. R. Vascular plant systematics. New York: Harper \& Row, 1974. $891 \mathrm{p}$

SACCO, J. C. Passifloraceas. In: REITZ, R. (Ed.). Flora Ilustrada Catarinense. Itajaí: Herbário Barbosa Rodrigues, 1980. p. 1-130.

SAMPAIO, E. V. S. B; PAREYN, F. G. C.; FIGUEIRÔA, J. M.;
SANTOS JR., A. G. (Ed.). Espécies da flora nordestina de importância econômica potencial. Recife: Associação Plantas do Nordeste, 2005. 331 p.

SENA, T. S. N.; QUEIROZ, L. P. Passifloraceae. In: GUEDES, M. L. S.; JORGE, M. D. R. (Ed.). Checklist das espécies vasculares do Morro do Pai Inácio (Palmeiras) e Serra da Chapadinha (Lençóis), Chapada Diamantina, Bahia - Brasil. Salvador: Universidade Federal da Bahia, 1998. p. 26.

SILVA, E. O.; SANTOS, J. U. M.; DIAS, A. C. A. Passifloraceae na área de proteção ambiental de Belém, PA, Brasil. Rodriguésia, Rio de Janeiro, v. 64, n. 4, p. 829-845, 2013.

SZABO, A. V.; ROCHA, A. C. S.; TOSATO, J. A. C.; BARROSO, W. Área de Proteção Ambiental (APA) Serra Branca/Raso da Catarina. In: MARQUES, J. (Org.). As caatingas: debates sobre a ecorregião do Raso da Catarina. Paulo Afonso: Fonte Viva, 2007. p. 21-40.

THIERS, B. [continuously updated]. Index Herbariorum: a global directory of public herbaria and associated staff. 2015. New York: New York Botanical Garden's Virtual Herbarium. Disponível em: $<$ http://sweetgum.nybg.org/ih/>. Acesso em: 23 mar. 2015.

ULMER, T.; MACDOUGAL, J. M. Passiflora: passionflowers of the world. Cambridge: Timber Press, 2004. 430 p.

VANDERPLANK, J. A Revision of Passiflora section Dysosmia: Passifloraceae. Curtis's Botanical Magazine, Hoboken, v. 30, n. 4, p. 318-387, 2013.

VELlOSO, A. L.; SAMPAIO, E. V. S. B.; PAREYN, F. G. C. Ecorregiões propostas para o bioma Caatinga. Recife: Associação Plantas do Nordeste, 2002. 80 p.

VITTA, F. A. Passifloraceae. In: STANNARD, B. L. (Ed.). Flora of the Pico das Almas Chapada Diamantina Bahia, Brazil. Kew: Royal Botanic Gardens, 1995. 877 p.

ZUCARELLI, V. Germinação de sementes de Passiflora cincinnata Mast: fases, luz, temperatura e reguladores vegetais. 2007. 111 f. Dissertação (Mestrado em Ciências Biológicas Botânica) - Universidade Estadual Paulista, Botucatu. 2007. 